\title{
Resposta plasmática de glicose e insulina em eqüinos alimentados com diferentes fontes de amido
}

\author{
Alexandre Augusto de \\ Oliveira GOBESSO ${ }^{1}$ \\ Mariano ETCHICHURY ${ }^{1}$ \\ Hugo TOSI $^{2}$
}

Correspondência para:

Alexandre Augusto de Oliveira Gobesso, Avenida Duque de Caxias Norte, 225,13630-000, Pirassununga, SP; (19) 35654222, cateto@usp.br

Recebido para publicação: 18/01/2007 Aprovado para publicação: 29/06/2009

\author{
1 - Departamento de Nutrição e Produção Animal da Faculdade de Medicina \\ Veterinária e Zootecnia da Universidade de São Paulo, Pirassununga-SP \\ 2 - Faculdade de Ciências Agrárias e Veterinárias da Universidade Estadual \\ Paulista, Jaboticabal-SP
}

Resumo

Palavras-chave:

O objetivo deste trabalho foi medir a resposta plasmática de glicose e insulina em cavalos alimentados com dietas contendo concentrados energéticos formulados com diferentes fontes de amido, tais como milho, aveia, sorgo e uma mistura de milho e aveia em partes iguais por peso. Foram utilizados quatro eqüinos com 36 meses de idade em media, mestiços, machos, castrados, com peso aproximado de $350 \mathrm{~kg}$. O delineamento experimental utilizado foi um quadrado latino 4X4 (quatro animais, quatro tratamentos, quatro períodos). Os resultados foram processados através de programa computacional, a normalidade dos resíduos verificada pelo Teste de Shapiro - Wilk, e as variâncias comparadas pelo teste $F$. Não foram observadas diferenças nos níveis de glicose plasmática entre tratamentos. No caso da glicose, todos os tratamentos atingiram seu máximo nível duas horas e meia pós-ingestão $\mathrm{O}$ nível de insulina plasmática foi significativamente inferior antes da refeição em aqueles cavalos tratados com a mistura de milho e aveia, e significativamente superior nos cavalos alimentados com milho como fonte de energia três horas e meia pós ingesta. Os valores de glicose e insulina plasmática observados neste estudo podem ter sido influenciados pelo processamento das dietas na forma peletizada, promovendo uma maior absorção de glicose no intestino delgado. As dietas contendo diferentes fontes de amido não influenciaram nem o tempo nem a quantidade de glicose absorvida no intestino delgado. As variações observadas nos níveis de insulina indicam que um manejo alimentar apropriado pode influenciar os níveis deste hormônio, moderando os seus efeitos indesejáveis.

\section{Introdução}

O conhecimento sobre nutrição, fisiologia da digestão e resposta fisiológica a diferentes dietas da espécie eqüina têm sido motivo de muitos trabalhos científicos, mas o avanço nas descobertas tem encontrado barreiras, principalmente no que tange ao metabolismo energético pós-absortivo.

O conhecimento da fisiologia da digestão dos eqüinos é essencial para práticas nutricionais consistentes, faz-se necessário conhecer não somente como o aparelho digestório funciona, mas o quão eficiente pode vir a ser. Do mesmo modo, estes conhecimentos não estão disponíveis nos sistemas de avaliação dos alimentos para eqüinos, e muitos países utilizam como alternativa, tabelas de composição de alimentos para ruminantes. ${ }^{1} \mathrm{O}$ conhecimento dos mecanismos digestivos tem aumentado consideravelmente com o uso de métodos adequados para avaliação do suprimento de nutrientes. ${ }^{2}$ Alguns estudos têm indicado que a análise química da composição em carboidratos dos alimentos oferecidos para os eqüinos pode não ser a melhor forma de prever a resposta glicêmica, mas a relação entre a glicose e a insulina imediatamente após a alimentação pode ser extremamente 
importante nesta avaliação. ${ }^{3}$

Os mecanismos glicoregulatórios nos cavalos, aparentemente, não têm sofrido avaliações criteriosas, apesar de serem importantes para a compreensão do comportamento plasmático da glicose, não somente nos casos de doenças, mas também como conseqüência da influência do exercício físico, tratamentos médicos ou nutricionais. Para ilustrar, a concentração de glicose plasmática é menor em pôneis alimentados com dieta contendo grãos, quando comparada com a de pôneis que comem feno; mas aumenta, e se equivale, quando estes animais recebem infusão intravenosa de glicose. ${ }^{4} \mathrm{~A}$ resistência à insulina em pôneis pode ser o resultado de seleção natural para sobreviver em condições climáticas desfavoráveis, com clima severo e falta de alimento, proporcionando um desvio metabólico que leva a maior parte do carboidrato ingerido para o fígado, onde são transformados em triglicérides, e não para os músculos. ${ }^{5}$

Esta adaptação metabólica dos pôneis é uma vantagem evolutiva para sobreviver em locais com pouca disponibilidade de alimento, mas é uma desvantagem para aqueles animais que foram domesticados e recebem maiores quantidades de alimento de boa qualidade e tem baixos níveis de atividade. Este fato é comprovado observando a facilidade com que os pôneis ganham peso. ${ }^{5}$

A ingestão de grandes quantidades de carboidratos solúveis tem sido apontada como responsável por alterar as concentrações plasmáticas de hormônios relacionados com o crescimento, particularmente os tireóideos. A quantidade de carboidratos ingerida influenciaria o metabolismo dos hormônios da tireóide, interferindo na conversão de tiroxina (T4) em triiodotironina (T3), mediada pela insulina. ${ }^{3}$

A glicose é a maior fonte de energia dos animais, e a glicólise proporciona a melhor reação enzimática para produção de ATP nas células; o transporte de glicose para o interior das células é o primeiro passo para sua utilização. ${ }^{6} \mathrm{~A}$ insulina é de fundamental importância na regulação dos processos metabólicos glicoregulatórios, mas um aumento na função das células b e uma hiperinsulinemia nos estados resistentes a insulina pode desconectar os receptores de insulina nos adipócitos de humanos e roedores. ${ }^{7}$ Estes ajustes também são associados com hipertrigliceridemia, devido ao aumento da síntese e secreção de lipoproteína hepática de muito baixa densidade (VLDL). É importante observar que as trocas plasmáticas de insulina são associadas à secreção e não a remoção. ${ }^{8,9} \mathrm{~A}$ mensuração da cinética de metabólitos na circulação periférica durante o dia pode explicar algumas trocas bioperiódicas envolvidas com a ingestão e absorção de nutrientes, e um aumento nos níveis de glicose após alimentação pode ser relacionado com absorção gastrintestinal, sugerindo que a forma do alimento, quantidade de fibras e interação amido-proteína podem modificar a resposta glicêmica. ${ }^{10}$

A concentração plasmática de glicose após a ingestão de alimento, chamada de resposta glicêmica, pode ser influenciada pelo tamanho da partícula do alimento, grau de processamento térmico, composição protéica, gordura e fibra, estrutura bioquímica do carboidrato, conteúdo e intervalo de tempo com a refeição anterior. ${ }^{11}$ Assim, eqüinos alimentados com concentrado farelado podem apresentar um pico de glicose plasmática aos 150 minutos após ingestão, enquanto que animais alimentados com concentrado peletizado, podem fazê-lo após 180 minutos, sugerindo que mais glicose deve ser absorvida com a dieta peletizada. ${ }^{12}$

Para completar a avaliação do índice glicêmico de um alimento, ou seja, a magnitude da resposta em glicose plasmática após sua ingestão, a concentração plasmática de insulina pode ser um bom indicativo da presença de açúcar na corrente sangüínea. ${ }^{13}$ Neste sentido, uma rápida resposta secretora de insulina pelo pâncreas pode ser associada à ingestão de grandes quantidades de energia e proteína. ${ }^{14}$ 
Num estudo feito com eqüinos que receberam alimento concentrado, foram observados valores plasmáticos de glicose e insulina maiores que aqueles que foram mantidos em regime de pastagem. ${ }^{15}$ Do mesmo modo, a avaliação dos resultados de absorção e teste de tolerância a glicose mostram que, dependendo do tipo de alimento ao que os cavalos estejam adaptados, seja volumoso ou concentrado, observam-se respostas plasmáticas diferentes. Os picos de insulina plasmática podem até triplicar com o aumento do amido na dieta, quando comparado com os valores anteriores à ingestão do alimento, e o momento do pico é inversamente proporcional à quantidade de amido ingerida. ${ }^{3}$

Níveis máximos de glicemia em eqüinos foram observados de 2 a 3 horas após a ingestão de alimento no período da manhã; em cavalos alimentados com feno de aveia e concentrado pode ser observada uma glicemia maior quando comparada a aqueles que se alimentam com feno de alfafa. Nestes animais a insulina teve o seu pico entre 3 a 4 horas após a alimentação. ${ }^{16}$ Em outro estudo ${ }^{17}$, foi constatado que a concentração plasmática de glicose aumenta $70 \%$ uma hora pós-alimentação, e a de insulina, até oito vezes duas horas após a alimentação.

Durante o jejum, quando a concentração de insulina é baixa, a disponibilidade de ácidos graxos não esterificados e a conseqüente oxidação de lipídios são favorecidas; por comparação, uma dieta rica em carboidratos aumenta a disponibilidade de glicose e insulina, e diminui a disponibilidade de ácidos graxos não esterificados. ${ }^{18} \mathrm{~A}$ quantidade de alimento ingerido e o tempo após a ingestão do mesmo são dois parâmetros importantes para avaliação de valores plasmáticos de insulina. ${ }^{14}$

O presente trabalho tem como objetivo quantificar os parâmetros sanguíneos do metabolismo da glicose e insulina em eqüinos alimentados com diferentes fontes de energia, e estabelecer relações entre eles.

\section{Material e Método}

O experimento foi conduzido nas dependências do Setor de Eqüideocultura do Campus da USP - Pirassununga, e no departamento de zootecnia da Faculdade de Ciências Agrárias e Veterinárias de Jaboticabal - UNESP, estado de São PauloBR. Foram utilizados quatro eqüinos machos, com idade média de 36 meses, peso médio de $350 \mathrm{~kg}$. Foi utilizado um delineamento experimental em Quadrado Latino 4x4 (quatro animais, quatro tratamentos e quatro períodos).

Os tratamentos foram compostos por uma fração volumosa (feno de gramínea - Cynodon dactylon (l.) Pers. var. Coast cross-1) e uma fração concentrada, peletizada, cuja variação foi a fonte de amido (Tabela 1).

$\mathrm{O}$ alimento foi fornecido em duas refeições, com intervalos constantes, as 07h00min e as $19 \mathrm{~h} 00 \mathrm{~min}$ horas, sendo a ração total (feno + concentrado) divididas em partes iguais entre os dois horários, adotando-se o consumo diário individual de $2,0 \%$ do peso vivo em MS ${ }^{19}$, sendo $40 \%$ de concentrado e $60 \%$ de volumoso. O volumoso foi oferecido ao mesmo tempo em que o concentrado, de acordo com o sugerido por Carvalho $^{20}$. As amostras de sangue foram coletadas por punção da veia jugular com agulha $40 \times 10 \mathrm{~mm}$, em tubos coletores a vácuo (Vacutainerâ-BD), as 07h30min (30), 08h30min (90), 09h30min (150) e $10 \mathrm{~h} 30 \mathrm{~min}$ (210), antes e durante a ingestão da dieta oferecida pela manhã (07h00min horas) para dosagem de glicose e insulina, seguindo o modelo proposto por Stull e Rodiek ${ }^{3}$.

As análises de glicose plasmática foram feitas pelo método enzimático, utilizando a técnica descrita por Bergmeyer ${ }^{21}$ e Tonkk ${ }^{22}$, e a insulina plasmática foi analisada com quimiluminescência, com o método descrito por Yalow e Berson ${ }^{23}$. Os resultados foram processados através do programa computacional Statistical Analysis System ${ }^{24}$, sendo verificada a normalidade dos resíduos pelo Teste de Shapiro - Wilk, e as variâncias comparadas pelo teste $\mathrm{F}$. Os dados originais 
Tabela 1 - Composição bromatológica em porcentagem dos quatro concentrados energéticos e do feno usados no experimento - São Paulo - 1998

\begin{tabular}{|c|c|c|c|c|c|c|c|c|c|c|c|}
\hline \multirow{2}{*}{ Tratamento } & \multicolumn{10}{|c|}{ Fração Alimentar } & \multirow[b]{2}{*}{ Amido } \\
\hline & MS & MO & $\mathrm{MM}$ & $\mathrm{EE}$ & FB & PB & $\mathrm{Ca}$ & $\mathrm{P}$ & FDN & FDA & \\
\hline Aveia & 90,59 & 83,20 & 7,39 & 3,43 & 8,82 & 21,12 & 0,80 & 0,29 & 26,21 & 13,59 & 46,67 \\
\hline Milho & 90,82 & 83,61 & 7,21 & 4,00 & 7,54 & 18,99 & 0,71 & 0,73 & 24,77 & 12,74 & 47,54 \\
\hline Sorgo & 90,27 & 80,55 & 9,72 & 1,52 & 10,19 & 17,34 & 0,56 & 0,64 & 28,88 & 17,85 & 47,30 \\
\hline Milho/Aveia & 90,81 & 80,43 & 10,38 & 3,20 & 9,34 & 15,29 & 0,89 & 0,74 & 29.78 & 14,49 & 43,67 \\
\hline \multirow[t]{2}{*}{ Feno } & 90,75 & 85,5 & 5,25 & 0,44 & 35,95 & 3,61 & 0,07 & 0,16 & 86,79 & 46,12 & 6,30 \\
\hline & \multicolumn{11}{|c|}{ Formulação dos quatro concentrados experimentais, em porcentagem } \\
\hline Tratamento & & F. Soja ${ }^{1}$ & F. Trigo ${ }^{2}$ & Milho & Aveia & Sorgo & $\mathrm{M} / \mathrm{A}$ & C. Soja ${ }^{3}$ & Núcleo & Calcita & Sal \\
\hline Milho & & 12 & 24,6 & 47,5 & - & - & - & 10 & - & 3 & 1 \\
\hline Aveia & & 9,2 & 25 & - & 60 & - & - & - & 1,8 & 3 & 1 \\
\hline Sorgo & & 8 & 27,8 & - & - & 48,5 & - & 10 & 1,9 & 2,8 & 1 \\
\hline Milho/Avei & & 10 & 30 & - & - & - & 51,7 & 2,5 & - & 4,8 & 1 \\
\hline
\end{tabular}

Notas: MS: matéria seca, MO: matéria orgânica, MM: matéria mineral, EE: extrato etéreo, FB: fíbra bruta, PB: proteína bruta, Ca: cálcio, P: fósforo, FDN: fíbra solúvel em detergente neutro, FDA: fíbra solúvel e detergente ácido. ${ }^{1}$ Farelo de soja tostado, ${ }^{2}$ Farelo de trigo, ${ }^{3}$ Casca de soja, M/A: milho e aveia

ou transformados, quando este último procedimento foi necessário, foram submetidos à análise de variância usando o modelo geral linear. ${ }^{24}$ Foi adotado um nível de significância de 5\%.

\section{Resultados e Discussão}

Foi observado um aumento nos valores de glicose plasmática nas medidas realizadas após a ingestão das dietas $(\mathrm{p}<0,005)$, mas não foram observadas diferenças entre tratamentos $(p>0,05)$ nos valores de glicose plasmática (Tabela 2), a semelhança do verificado por Sticker et al..$^{25}$, que observaram que a concentração plasmática de glicose e insulina não foi afetada pelos níveis de proteína e energia da dieta. Os valores de insulina plasmática aumentaram significativamente $(\mathrm{p}<0,05)$ após a ingestão das dietas (Tabela 3), em correspondência com aumento de glicose plasmática; também foram observadas diferenças significativas $(\mathrm{p}<0,05)$ entre tratamentos, para os valores médios de insulina plasmática no tempo -30 , sendo

Tabela 2 - Valores médios glicose plasmática em miligramas por cento (mg \%), de amostras de sangue coletadas 30 (-30) minutos antes e 30, 90, 150 e 210 minutos após a alimentação no período matutino em eqüinos alimentados com concentrados à base de milho, aveia, sorgo e milho/aveia - São Paulo - 1998

\begin{tabular}{lccccc}
\hline \multirow{2}{*}{ Tratamento } & \multicolumn{5}{c}{ Tempo } \\
\cline { 2 - 6 } & -30 & 30 & 90 & 150 & 210 \\
\hline Milho & $86,93 \mathrm{aA}$ & $100,20 \mathrm{aB}$ & $150,33 \mathrm{aC}$ & $161,63 \mathrm{aC}$ & $157,13 \mathrm{aC}$ \\
Aveia & $86,23 \mathrm{aA}$ & $85,06 \mathrm{aA}$ & $110,73 \mathrm{aB}$ & $123,23 \mathrm{aB}$ & $116,53 \mathrm{aB}$ \\
Sorgo & $88,03 \mathrm{aA}$ & $98,93 \mathrm{aB}$ & $133,43 \mathrm{aC}$ & $145,70 \mathrm{aC}$ & $145,03 \mathrm{aC}$ \\
Milho/Aveia & $85,60 \mathrm{aA}$ & $98,40 \mathrm{aB}$ & $133,93 \mathrm{aC}$ & $140,57 \mathrm{aC}$ & $130,40 \mathrm{aC}$ \\
\hline
\end{tabular}

${ }^{\text {a }}$ Médias seguidas da mesma letra minúscula nas colunas não diferem pelo teste de Tukey( $\left.\mathrm{p}>0,05\right)$. ${ }^{A}, \mathrm{~B}, \mathrm{C}$ Médias seguidas de letras maiúsculas diferentes na mesma linha diferem pelo teste de Tukey $(p<0,05)$

Tabela 3 - Valores médios de insulina plasmática $(\mathrm{mUl} / \mathrm{mL})$, de amostras de sangue coletadas $30(-30)$ minutos antes e 30, 90, 150 e 210 minutos após a alimentação no período matutino em eqüinos alimentados com concentrados a base de milho, aveia, sorgo e milho/aveia - São Paulo - 1998

\begin{tabular}{lccccc}
\hline \multirow{2}{*}{ Tratamento } & \multicolumn{5}{c}{ Tempo } \\
\cline { 2 - 6 } & -30 & 30 & 90 & 150 & 210 \\
\hline Milho & $6,17 \mathrm{aA}$ & $16,93 \mathrm{aAB}$ & $49,73 \mathrm{aB}$ & $85,93 \mathrm{aBC}$ & $126,03 \mathrm{aC}$ \\
Aveia & $7,00 \mathrm{aA}$ & $14,30 \mathrm{aB}$ & $36,90 \mathrm{aBC}$ & $56,97 \mathrm{aC}$ & $84,20 \mathrm{bD}$ \\
Sorgo & $7,83^{\mathrm{aA}}$ & $18,00 \mathrm{aB}$ & $48,73 \mathrm{aC}$ & $74,47 \mathrm{aD}$ & $73,03 \mathrm{bD}$ \\
Milho/Aveia & $5,40 \mathrm{bA}$ & $16,53 \mathrm{aB}$ & $53,07 \mathrm{aC}$ & $76,80 \mathrm{aC}$ & $75,23 \mathrm{bC}$ \\
\hline
\end{tabular}

Notas: a,A Médias seguidas de letras minúsculas diferentes na mesma coluna, e de letras maiúsculas na mesma linha, diferem $(\mathrm{p}<0,05)$ pelo teste de Tukey 
inferiores para o tratamento Milho/Aveia em relação aos demais, e no tempo 210 , onde os eqüinos alimentados com a dieta a base de milho apresentaram valor médio superior aos demais tratamentos. Pode-se inferir a partir destes dados que uma dieta cuja fonte energética seja um concentrado a base de uma mistura de milho e aveia em partes iguais promove menores valores basais de insulina, situação considerada desejável para cavalos estabulados, por evitar transtornos relacionados a altos níveis de insulina circulante. Curiosamente, a dieta contendo só milho apresenta um nível significativamente alto de insulina no tempo 210, resultando maior inclusive ao do tratamento Aveia, a pesar de o milho conter um amido que por suas características bioquímicas disponibiliza praticamente a metade de glicose da aveia para a digestão enzimática e absorção no intestino delgado. ${ }^{26}$

Neste experimento, as concentrações plasmáticas de glicose aumentaram após o fornecimento das dietas, e indicam, em coincidência com os resultados obtidos por Depew et al. ${ }^{17}$, que a concentração plasmática de glicose sofre uma elevação expressiva geralmente 60 minutos após a alimentação.
Neste estudo, a concentração de glicose plasmática aumentou até 90 minutos após a ingestão de alimento nos animais que se alimentaram com as dietas dos tratamentos Milho, Aveia, Sorgo e Milho/Aveia em cerca de $73 \%, 28 \%, 52 \%$ e $56 \%$, respectivamente, e a concentração de insulina aumentou $707 \%$, $427 \%, 522 \%$ e $883 \%$ respectivamente, para as mesmas dietas, resultados semelhantes aos observados por Depew et al. ${ }^{17}$ onde, nos cavalos, a concentração plasmática de glicose, 1 hora após alimentação aumentou $70 \%$ e a de insulina, 2 horas após a alimentação, aumentou oito vezes.

$\mathrm{Na}$ avaliação das curvas plasmáticas de insulina e glicose (Figuras 1 e 2) é possível observar que os picos ocorreram, no caso da insulina, duas horas e meia nos tratamentos Sorgo e Milho/Aveia, e três horas e meia nos tratamento Milho e Aveia após a alimentação; no caso da glicose todos os tratamentos atingiram seu máximo nível duas horas e meia pós-ingestão; estes resultados são semelhantes aos observados por Stull e Rodiek ${ }^{3}$, que concluíram que a ingestão de carboidratos induz níveis de glicose e insulina, em eqüinos, quantitativamente semelhantes aos humanos; entretanto, o pico de absorção de glicose nos

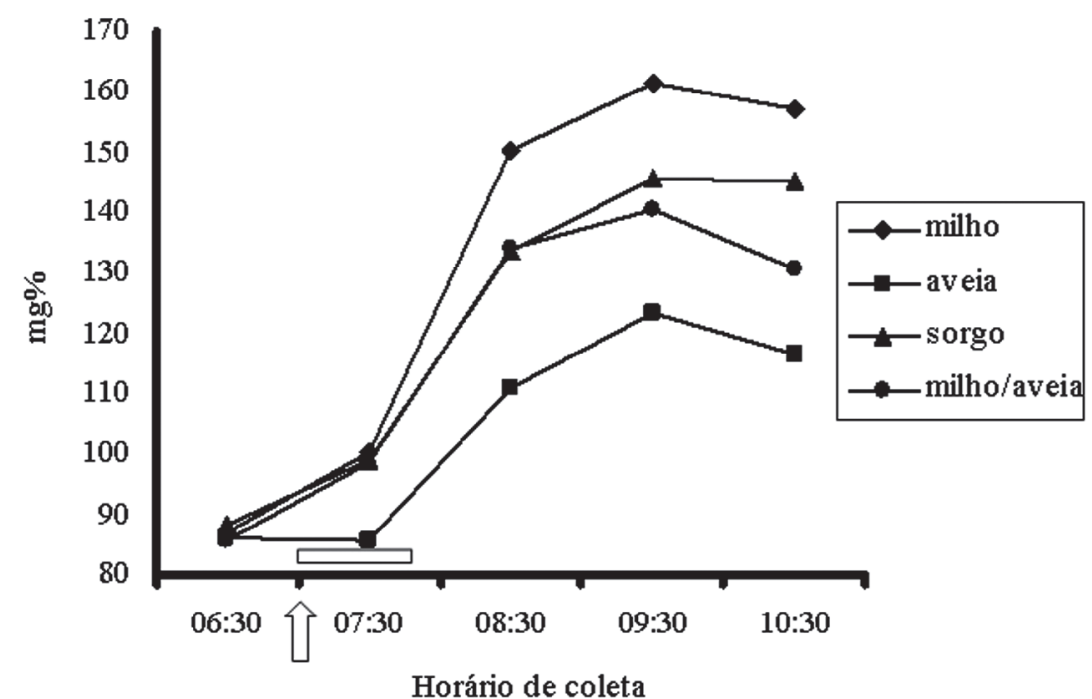

$\Uparrow \quad$ Momento do fornecimento das dietas, $\square$ Tempo de ingestão dos concentrados.

Figura 1 - Valores plasmáticos de glicose em miligramas, de amostras de sangue coletadas 30 (-30) minutos antes e $30,90,150$ e 210 minutos após a alimentação no período matutino de eqüinos alimentados com concentrados a base de milho, aveia, sorgo e milho/aveia em partes iguais - São Paulo - 1998 


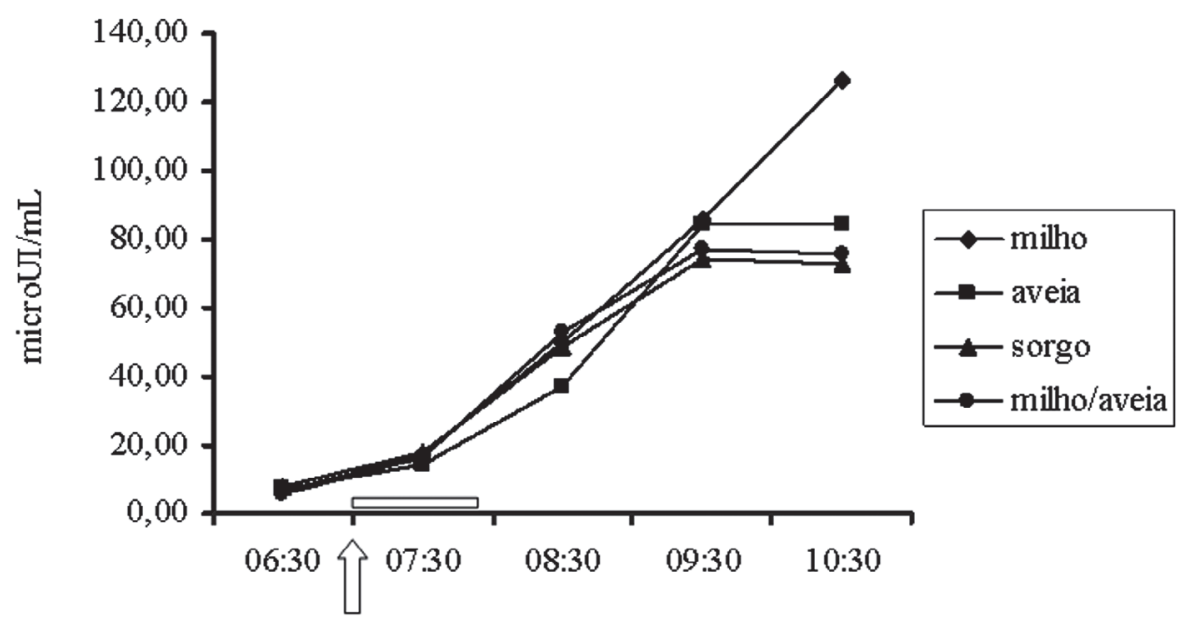

Horário de Coleta

$\Uparrow$ Momento do fornecimento das dietas, $\square$ Tempo de ingestão dos concentrados.

Figura 2 - Valores de insulina plasmática em $\mathrm{mUI} / \mathrm{mL}$ de amostras de sangue coletadas 30 (-30) minutos antes e 30, 90,150 e 210 minutos após a alimentação no período matutino, de eqüinos alimentados com concentrados a base de milho, aveia, sorgo e milho/aveia em partes iguais - São Paulo - 1998

cavalos ocorreria mais tarde que nos humanos. Com resultados semelhantes, Witham e Stull ${ }^{16}$ relataram que o pico de glicose plasmática foi obtido de 2 a 3 horas após a ingestão de alimento no período da manhã, e o de insulina entre 3 a 4 horas após alimentação. Trabalhos feitos por Healy, Siciliano e Lawrence ${ }^{12}$ indicaram que eqüinos alimentados com concentrado farelado apresentaram um pico de glicose plasmática aos 150 minutos após ingestão, enquanto que, os alimentados com concentrado peletizado, mostraram este pico após 180 minutos, sugerindo que mais glicose foi absorvida com a dieta peletizada. A absorção máxima da dieta peletizada neste estudo ocorreu no mesmo intervalo de tempo que a dieta farelada do estudo de Healy, Siciliano e Lawrence ${ }^{12}$. Nesse mesmo estudo, foi comunicado que não houve diferença entre tratamentos para os níveis plasmáticos de insulina, resultados que não coincidem com os achados deste estudo, onde pode ser observado que existem diferenças entre fontes de energia para este parâmetro, consolidando a idéia de que mais trabalhos nesta área devem ser praticados para chegar a conclusões mais acertadas.

Segundo achados de Potter et al. ${ }^{26}$, a peletização pode aumentar a digestibilidade do amido no intestino delgado, tanto que, alimentos peletizados produzem um grande aumento na concentração de glicose e insulina plasmática, quando comparados com alimentos menos processados. Cabe ressaltar que os concentrados energéticos utilizados neste experimento foram peletizados, e que este tipo de processamento pode influenciar notadamente o processo de mastigação, salivação e a digestão enzimática do amido, e por tanto os valores de glicose e insulina plasmática. ${ }^{11,25}$

\section{Conclusões}

As dietas para eqüinos formuladas com diferentes fontes de amido não parecem diferir nem na quantidade nem no tempo em que a glicose é absorvida no intestino delgado; porem, as variações observadas nos níveis de insulina são indicativas de que um manejo alimentar apropriado pode influenciar tanto os níveis basais como os picos deste hormônio, moderando os seus efeitos indesejáveis.

\section{Agradecimentos}

À Fundação de Amparo e Pesquisa do Estado de São Paulo, pelo apoio financeiro (processo 99/03278). 


\section{Plasmatic response of glucose and insulin in horses fed diets containing different starch sources}

\section{Abstract}

Key words:

Equine.

This study was aimed to measure the plasmatic response of glucose and insulin of horses fed diets containing different starch sources, like corn, oat, sorghum and a mix of corn and oat in equal parts. Four standarbred gelding 36 month old an weighing average of $350 \mathrm{~kg}$ were used in a Latin Square 4 x 4 (four animals, four treatments and four period) trial design. No statistical differences were observed in plasmatic glucose levels either before or after ingestion between treatments. Maximum plasmatic level of glucose was observed in all diets two and a half hours post ingestion. Insulin plasmatic level was significantly lower before ingestion in horses treated with the mixed corn and oat diet, when compared with the other treatments. In the other hand, the insulin plasmatic level in horses fed corn-formulated diet was statistically higher than the others treatments at three hours and a half after ingestion. Diets containing different sources of starch had no effect in time neither quantity of glucose absorbed in small intestine. Variation observed in insulin plasmatic levels indicate that a proper feeding can have a regulatory effect of this hormone, avoiding undesirable's behaviors.

\section{Referências}

1 HINTZ, H. F. Horse nutrition. New York: Arco Publishing, 1983. 228 p.

2 TISSERAND, J. L. Non-Ruminants herbivores; horses and rabbits. Livestock Production Science, v. 19, p. 279-288, 1988.

3 STULL, C. L.; RODIEK, A. V. Responses of blood glucose, insulin and cortisol concentrations to common equine diets. American Institute of Nutrition, v. 118, n. 2, p. 206-213, 1988.

4 GARCIA, M. C.; BEECH, J. Equine intravenous glucose tolerance test: Glucose and insulin responses of healthy horses fed grain or hay and of horses with pituitary adenoma. American Journal of Veterinary Research, v. 47, n. 3, p. 570-572, 1986.

5 JEFFCOOTT, L. B.; FIELD, J. R. Glucose tolerance and insulin sensitivity in ponies and standard bred horses. Equine Veterinary Journal, v. 18, n. 2, p. 97101, 1986.

6 ARAI, T.; WASHIZU, T.; HAMADA, S.; SAKO, T.; TAKAGI, S.; YASHIKI, K.; MOTOYOSHI, S. Glucose transport and glycolitic enzyme activities in erythrocytes of two-year-old thoroughbreds undergoing training exercise. Veterinery Research Committe, v. 18, n. 6, p. 417-422, 1994.

7 FORHEAD, A. J.; FRENCH, J.; IKIN, P.; FOWLER, J. $\mathrm{N} . ;$ DOBSON, H. Relationship between plasma insulin and triglyceride concentrations in hypertriglyceridaemic donkeys. Research in Veterinary Science, v. 56, n. 3, p.
389-392, 1994.

8 MADIGAN, J. E.; EVANS, J. W. Insulin turnover and irreversible loss rate in horses. Journal of Animal Science, v. 36, n. 4, p. 730-733, 1973.

9 GIRAUDET, A.; HINCHCLIFF, K. W.; KOHN, C. W.; MCKEEVER, K. H. Early insulin response to an intravenous glucose tolerance test in horses. American Journal of Veterinary Research, v. 55, n. 3, p. 379-381, 1986.

10 GREPPI, G. F.; CASINI, L.; GATTA, D.; ORLANDI, M.; PASQUINI, M. Daily fluctuations of hematology and blood biochemistry in horses fed varying levels of protein. Equine Veterinary Journal, v. 28, n. 5, p. 350353, 1996.

11 GUEZENNEC, C. Oxidation rates, complex carbohydrates and exercise. Sports Medicine, v. 19, n. 6, p. 365-372, 1995.

12 HEALY, H. P.; SICILIANO, P. D.; LAWRENCE, L. $M$. Effect of concentrate form on blood and gastric fluid variables in ponies. Equine Nutrition and Physiology Society, v. 15, n. 10, p. 423-428, 1995.

13 RANKIN, J. W. Glycemic index and exercise metabolism. Sports Science Exchange, v. 10, n. 1, p. 23-31, 1997.

14 GLADE, M. J.; GUPA, S.; REIMERS, T. J. Hormonal responses to high and low planes of nutrition in weanling Thoroughbreds. Journal of Animal Science, v. 59, p. 658-665, 1984.

15 LACERDA NETO, J. C.; URBINATI, E. C.; ROSA E 
SILVA, A. A. M.; SANTOS, G. F. Influence of nutrition on the glucose absorption and tolerance test in horses submitted to different fasting periods. Arquivo Brasileiro de Medicina Veterinária e Zootecnia, v. 50, n. 6, p. 685-690, 1998.

16 WITHAN, C. L.; STULL, C. L. Metabolic responses of chronically starved horses to reffeding with three isoenergetic diets. Journal of American Veterinary Medicine Association, v. 212, n. 5, p. 691-696, 1998.

17 DEPEW, C. L.; THOMPSON JR., D. L.; FERNANDEZ, J. M.; STICKER, L. S.; BURTEIGH, D. W. Changes in concentration of hormones, metabolites, and amino acids in plasma of adult horses relative to overnight feed deprivation followed by a pellet-hay meal feet at noon. Journal of Animal Science, v. 72, n. 6, p.1530-1539, 1994.

18 SHERMAN, W. M.; PEDEN, M. C.; WRIGHT, D. Carbohydrate feedings one hour before exercise improve cycling performance. American Journal of Clinical Nutrition, v. 54, p. 866-870, 1991.

19 NATIONAL RESEARCH COUNCIL. Nutrient requirements of horses. 5. ed. Washington: National Academy of Science, 1989. 100 p.

20 CARVALHO, M. A. G. Digestibilidade aparente em eqüinos submetidos a três condutas de arraçoamento. 1992. 34 f. tese (Mestrado) - Escola de Veterinária, Universidade Federal de Minas Gerais, Minas Gerais, 1992.

21 BERGMEYER, H. V. Methods of enzymatic analysis. 2. ed. New York: Academic Press, 1987. p. 1205-1214.

22 TONKK, D. B. Quality control in clinical laboratories, diagnostic reagents division. Canada: Sear Borough, 1972

23 YALOW, R. S.; BERSON, S. A. Immunoassay of plasma insulin in a man. Journal of Clinical Investigation, v. 39, p. 1401, 1960.

24 STATISTICAL ANALISYS SYSTEM. SAS user's guide: statistics. Versão 5. Cary: SAS, 1995.

25 STICKER, L. S.; THOMPSON JR., D. L.; BUNTING. L. D.; FERNANDEZ, J. M.; DEPEW, C. L. Dietary protein and (or) energy restriction in mares: Plasma glucose, Insulin, nonesterified fatty acid and urea nitrogen responses to feeding, glucose e epinephrine. Journal of Animal Science, v. 73, n. 1, p. 136-144, 1995.

26 POTTER, G. D.; ARNOLD, F. F.; HOUSEHOLDER, D. D.; HANSEN, D. H. Digestion of starch in the small or large intestine of the equine. In: EUROPEAN CONFERENCE ON HORSE NUTRITION, 1., 1992, Hannover, Germany. Proceedings... 1992. p. 107-111. 